\title{
The Case for Emissions Egalitarianism
}

\section{Olle Torpman ${ }^{1,2,3}$ (iD}

Accepted: 9 July 2019 / Published online: 23 July 2019

(C) The Author(s) 2019

\begin{abstract}
There is a fixed limit on the greenhouse gas emissions that the atmosphere can absorb before triggering dangerous climate changes. One of the debates in climate ethics concerns how the available emissions should be divided between people. One popular answer, sometimes called "Emissions Egalitarianism" (EE), proposes a distribution of emissions permits that gives everyone an equal per capita share of the atmospheric absorptive capacity. However, several debaters have objected to EE. First, it has been argued that there is no principled reason to accept EE, since it cannot be justified on the basis of any moral theory. Second, it has been argued that there is neither any pragmatic reason to accept EE, since it is impracticable, politically unfeasible, and fails to reach its goal. This paper defends EE against these objections. First, it shows that EE can be justified on libertarian, utilitarian, and fairness grounds, respectively. Second, it shows that EE is neither more impracticable, nor more politically unfeasible, than its rivals. It also argues that EE does not fail to reach its goal. Consequently, there is a case to be made for EE.
\end{abstract}

Keywords Climate ethics Emissions rights Climate justice $\cdot$ Egalitarianism Emissions permits

\section{Introduction}

There is a fixed limit on the volume of greenhouse gases that the atmosphere can naturally absorb, before triggering climate changes that cause human (and nonhuman) harm. This absorptive capacity of the atmosphere provides an ecosystem service that can be treated as a common global good. One of the debates in climate ethics

Olle Torpman

olle.torpman@philosophy.su.se

1 Department of Philosophy, Stockholm University, Universitetsvägen 10D, SE-106 91 Stockholm, Sweden

2 Institute for Futures Studies, Stockholm, Sweden

3 Department of Animal Environment and Health, Swedish University of Agricultural Sciences, Stockholm, Sweden 
concerns the question of how the atmosphere's absorptive capacity, in terms of emissions permits, should be divided between people.

Several principles have been proposed for answering this question. One popular principle, sometimes called Emissions Egalitarianism (EE), says that every person should have the same right as everyone else to emit greenhouse gases. ${ }^{1}$ It proposes a distribution of emissions permits that gives everyone an equal per capita share of the atmospheric absorptive capacity. EE has been advocated by, for instance, Meyer (1999), Attfield (2003), Jamieson (2005), Singer (2010), Ott (2010), and Broome (2012). ${ }^{2}$ The intuition behind EE is, to borrow Broome's words, that "[i]t seems obvious that no one in the world has a stronger claim to this resource [i.e. permits to emit greenhouse gas] than anyone else, so it should be divided equally between people" (2012: 70).

Other authors, however, have raised objections to EE. For instance, it has been argued that although it appears at first sight to be an attractive view, a closer inspection reveals that there are in fact no moral arguments in its favor. For instance, Eric Posner and David Weisbach argue that there is "a series of welfare-related and pragmatic problems with the per capita approach" (2010: 122); Simon Caney argues that "we have no reason to accept the claim that greenhouse gas emissions should be distributed on an equal per capita basis" (2012: 299-300); Yoram Margalioth and Yinon Rudich argue that EE fails because it is "not grounded in any general moral principle and therefore cannot provide an answer to the question regarding what would be a fair allocation of emissions rights" (2013: 191); Thom Brooks argues that EE is implausible since "equal sizes [of emissions permits] may not be fair" (2016: 122); Dominic Roser and Christian Seidel argue similarly that EE "loses plausibility from a moral point of view" because it "fails to take account of differences in responsibility for the problem, of advantages resulting from the causation of the problem, of capabilities of dealing with the problem, or of differences between the needs of various people" (2017: 156); and Christian Baatz and Konrad Ott argue that EE ignores important aspects of both climate mitigation and climate adaptation, and therefore "EE fails as an ideal principle" (2017: 189). ${ }^{3}$

Roughly, the arguments levelled against EE can be divided in two camps: (i) principled arguments and (ii) pragmatic arguments. My aim in this paper is to defend EE. In section 2, I clarify how EE should be understood in more detail. In the section 3, I answer the principled objections leveled against EE, and provide some positive principled arguments in its favor. In the section 4, I answer the pragmatic objections against EE, and provide some positive pragmatic arguments in its favor. In section 5, I conclude that since the arguments against EE can be refuted, and since some positive arguments can be given in its support, there is a case to be made for EE.

\section{What Is Emissions Egalitarianism?}

EE says that everyone has an equal right to emit, and that everyone should thus have the same number of emissions permits (where each permit entitles an equal amount of emissions). In that sense, EE provides an answer to the question of how much greenhouse gas an individual or a country may emit, morally speaking. Although this might seem clear enough, there are

\footnotetext{
${ }^{1}$ It has also been called the Equal per Capita View. See, e.g. Posner and Weisbach (2010), and Caney (2012). In this paper, I will stick to the former label.

${ }^{2}$ See also Ott and Baatz (2012). Note, however, that both Ott and Baatz changed their views in their (2017).

${ }^{3}$ It should be noted that Baatz and Ott (2017: 194-5) think that EE is not implausible from a pragmatic view.
} 
some details that need to be spelled out before we can evaluate how EE fares as a principle for emissions distribution.

It should first be emphasized that the basic good at issue is the usages of the atmospheric absorptive capacity - or, in other words, permits to emit greenhouse gas. ${ }^{4}$ In the literature, this good is discussed variously in terms of "emissions rights", "emissions entitlements" and "emissions permits". For the sake of simplicity, and for the sake of not being biased towards rights-based moral theories, I will throughout this paper stick to the latter term. In any case, it is not actual emissions that matters according to EE, but rather permissions to emit. Given that emissions trading is allowed, the former is not the same as the latter. ${ }^{5}$

It should also be noticed that climate ethicists are not basically interested in emissions permits as such, but rather in the benefits that can be produced by emissions permits (e.g. capabilities or opportunities for wellbeing). Still, EE is not directly concerned with the distribution of those benefits, but rather with the distribution of an important resource (i.e. emissions permits) considered as a means to such benefits.

In connection to this, there is a debate whether emissions permits should be distributed in isolation from, or in integration with, other goods. There is also a debate whether or not we should divide the burdens of climate change mitigation and adaptation as a whole. There is thus a divide in climate ethics between so called "integrationists" and "isolationists". 6 To isolationists, $\mathrm{EE}$ is a fair enough solution to one specific climate problem - i.e., to how the available carbon budget should be divided. To integrationists, however, EE is implausible for disregarding other burdens of climate change as well as other considerations of justice. As Caney asks: "why should this one particular good (emitting greenhouse gases) have its own principle regulating it and why should this principle be equality?" (2011: 90). Since this critique is embedded in several of the other arguments raised against EE, I will deal with it in my discussion of these arguments in sections 3 and 4.

At any rate, it is important to clarify the level of theorizing at which EE operates. Climate ethicists often point out that there are first-level as well as second-level principles. At the first level, we find fundamental normative theories (such as egalitarianism, sufficientarianism, libertarianism, utilitarianism, and so on). At the second level we find, among other principles, specific principles for distribution of emissions permits (such as EE and its rivals). Since all second-level principles are justified primarily on the basis of first-level principles, the plausibility of a second-level principle (like EE) depends on the justification it can get from firstlevel principles. ${ }^{7}$ As we shall see below, most objectors to EE have argued that it cannot be justified on the basis of any first-level principle.

As this suggests, any specific principle for distribution of emissions permits, including all the rivals of EE, is second-level. Something should therefore be said about these other principles. Roughly, there are two main rivals to EE: a grandfathering principle, and a subsistence principle. The grandfathering principle takes reliance on emissions (depending on lifestyles, investments, plans and preferences for the future, etc.) as its main consideration. ${ }^{8}$ The subsistence principle takes people's needs as its main consideration. ${ }^{9}$ Since both reliance and needs

\footnotetext{
${ }^{4}$ See Broome (2012: 69): "The good we are concerned with [...] is annual permits to emit greenhouse gas".

${ }^{5}$ See Caney (2012: 256, f.n. 3).

${ }^{6}$ See Ott and Baatz (2012), and Caney (2012).

7 See Caney (2005: 2-3).

${ }^{8}$ See Margalioth and Rudich (2013). For a defense of the grandfathering principle, see Bovens (2011). For a critical examination, see Knight (2013).

${ }^{9}$ For a defense of the subsistence principle, see Shue (1993).
} 
differ between people, none of these principles recommend an equal per capita share of emissions permits. Although there are more to say about these principles, and although there might be further principles worth considering as well, what has been said here suffices for the purposes of this paper. ${ }^{10}$

The debate regarding which distribution principle is most plausible centers around mainly two adequacy conditions: one about desirability, the other about achievability. In Caney's words, a principle for emissions distribution should yield a recommendation that" is normatively compelling and that can be attained given the state of the natural world" (2012: 295, my emphases). The desirability condition concerns how EE fares from a perspective of morality or fairness. Posner and Weisbach (2010: 142) discuss this condition in terms of "issues of principle", while Baatz and Ott discuss it simply in terms of "justice" (2017: 185). This relates to the justification of EE on the basis of first level normative theories, as mentioned above. The achievability condition, on the other hand, concerns pragmatic considerations - i.e., how well EE fares from a perspective of practicality or political feasibility. EE has been criticized for failing to meet both of these conditions - i.e., for being both undesirable and unachievable.

These conditions suggest - just as was indicated in section 1 - that the objections against EE can be divided into two camps: (i) principled arguments, and (ii) pragmatic arguments. In the following sections, I answer these types arguments one at a time.

\section{Principled Arguments for EE}

As explained above, EE is a second-level principle. Consequently, any principled justification of EE is based on some first-level normative theory. Many authors have argued that there is no such justificatory basis for EE. For instance, Margalioth and Rudich argue that EE is "not grounded in any general moral principle..." (2013: 191), and Posner and Weisbach argue that it "is not easy to justify from the standpoint of any ethical theory" (2010: 169). As we saw above, Caney argues in a similar vein that "we have no reason to accept the claim that greenhouse gas emissions should be distributed on an equal per capita basis" (2012: 299-300). ${ }^{11}$

In this section, I show that there are several first-level normative theories that yield support to EE. I start by examining libertarian arguments, and then I continue with utilitarian arguments for EE. Thereafter I also discuss some arguments for EE on the basis of fairness theories.

\footnotetext{
${ }^{10}$ Other principles discussed in the climate ethics debate include the Polluter Pays Principle (PPP), the Ability to Pay Principle (APP), the Beneficiary Pays Principle (BPP), and the Greenhouse Development Rights approach (GDR). While the first three of these principles are fairly simple, GDR is more complex. It is based on considerations regarding capacity, needs and responsibility alike, and aims at securing an equal right to development. However, while EE merely aims to answer how the available carbon budget should be distributed, all these other principles provide answers to the question of how the burdens of climate change mitigation and adaptation should be divided. Since these are different questions, I will not in this paper consider these principles as rivals to EE. I will, however, return to this point in section 4.

${ }^{11}$ Caney examines both egalitarian and non-egalitarian arguments in favor of EE, but concludes that they all fail. Interestingly, Caney thinks that the only non-egalitarian argument that has any promise at all for defending EE is sufficientarianism. Thus, he examines only sufficientarian and egalitarian arguments in favor of EE. Although I shall not here object to Caney's particular arguments from egalitarianism and sufficientarianism, I will discuss some other principled grounds for EE. In doing so, I will also respond to the other authors' counter-arguments to these moral grounds for EE.
} 


\subsection{Libertarian Arguments}

According to libertarianism, people have rights to use whatever they morally own. If the atmospheric absorptive capacity can be regarded as a common global good that initially belongs to everyone, it could be argued that every person owns an equal part of it and hence has an equal right to use it for its carbon sink capacity. This argument has been given by, for instance, Moellendorf (2011).

Baatz and Ott raise several objections against this libertarian justification of EE. First, they argue that since it is impossible to privately appropriate the atmosphere, and since appropriation is a prerequisite for libertarian ownership rights, no agent can have any rights to the atmospheric sink capacity. Hence, this cannot support the view that everyone has an equal right to it either. They say that " $[t]$ he property rights that (right) libertarians are so keen to protect from infringements are different from the right to own parts of the earth's sink capacity. ... [T] he sink capacity is not created through investing one's labor, time, and/or money" (2017: 180).

This objection would be sound if it was the case that appropriation of a resource (such as the sink capacity) was possible only through the creation (or improvement) of that resource. But this is not the case. According to libertarianism, it is possible to appropriate a resource by means of discovering, labor-mixing, using, claiming, as well as through purchase, exchange or gift. ${ }^{12}$ As this implies, one does not have to create (or improve) a resource to appropriate it. Sure, it might be questionable to what extent the atmospheric capacity can be appropriated at all. However, this does not exclude that it initially belongs to everyone in common, thus providing people with equal rights of use.

Nevertheless, Baatz and Ott claim that "it is not clear why ownership rights of the earth's sink capacity trump considerations regarding (basic) needs" (2017: 181). This claim is rehearsed by Roser and Seidel: "[e]ven if it [i.e. the atmospheric absorptive capacity] does belong to everyone, equal ownership does not necessarily entail equal rights of use. A series of further relevant considerations (responsibility, needs, capabilities, benefits) actually support an unequal distribution of usage despite equal ownership" (2017: 157). Here, however, it can be replied that considerations regarding needs and capabilities, etcetera, begs the question against the libertarian view. Sure, one might see this objection as a reductio ad absurdum of libertarianism, but that is a separate debate.

Whether or not a right-libertarian defense of EE would succeed, EE can find support from a left-libertarian position. According to one version of left-libertarianism, so called Equal Share Left-Libertarianism, everyone has a right to an equal share of external resources (the atmospheric absorptive capacity included). ${ }^{13}$ The argument from this version of libertarianism builds on an interpretation on the proviso originally proposed by John Locke, according to which anyone is allowed to use resources only as long as there is an equal share of resources left for everyone else to use. This version of libertarianism suggests an equal division of emissions permits.

Against this idea, Roser and Seidel claim that "[p]erhaps the atmosphere belongs to nobody instead of everybody" (2017: 157). In a similar vein, Margalioth and Rudich argue that, "[w]e could assume that the atmosphere belongs to no one, rendering the equal per-capita argument baseless" (2013: 195). This, however, seems to confuse the doctrine of "res nullius" (that things belong to no-one) with the doctrine of "res communis" (that things belong to everyone).

\footnotetext{
12 See Vallentyne and van deer Vossen (2014).

${ }^{13}$ See, for instance, Vallentyne and van deer Vossen (2014), and Steiner (2009).
} 
From such confusion, no inference can be made against EE. ${ }^{14}$ Just because something does not belong to anyone, it does not mean that it may not be used by everyone. Indeed, leftlibertarianism is open to whether the atmosphere is initially owned by everyone or no one. The Lockean proviso, as interpreted by left-libertarians, restricts all kinds of usages of external resources - whether owned or unowned. Hence, people can have an equal liberty-right to use something even if that thing belongs to nobody. Therefore, it is possible to support EE on leftlibertarian grounds.

\subsection{Utilitarian Arguments}

There are both act-utilitarian and rule-utilitarian arguments to be given in favor of EE. According to rule-utilitarianism, a distribution is right if and only if it is required by a rule the general compliance with which (or the general acceptance of which) would produce the most good. ${ }^{15}$ The simple argument from rule-utilitarianism in favor of EE, considered as a rule for distributions of emissions permits, is that the general compliance with (or acceptance of) any other specific distribution rule, regarding emissions permits, would yield worse consequences than the general compliance with (or acceptance of) EE. I will get back to this shortly, as it relates to an act-utilitarian argument as well. Suffice it to say that, even if it might not be shown that rule-utilitarianism recommends EE exclusively, EE is at least not incompatible with the recommendations of rule-utilitarianism. And that is enough for my present purposes.

According to act-utilitarianism, a particular resource distribution, or any act in general, is right if and only if it maximizes welfare. A well-known act-utilitarian, Peter Singer, argues in favor of EE "because it seems likely to increase global welfare" (2010: 194). Singer argues accepting EE would, at least at an initial phase, push the political process forward towards a solution to the climate crisis, which is expected to have the best overall consequences. He says that this is "because of its simplicity, hence its suitability as a political compromise" (2010: 194). I will get back to this idea below, when I discuss pragmatic arguments in relation to EE (in section 4).

Another act-utilitarian argument for EE is that, since the welfare that is obtained from an additional good is typically declining, an equal distribution of goods is in general required for welfare maximization. Other things being equal, diminishing marginal utility (or welfare) thus implies that act-utilitarianism recommends an equal per capita distribution of emissions permits as well.

Posner and Weisbach object that since other things are not equal, this welfare-based consideration may instead suggest an unequal distribution of emissions permits:

[S]ome poor states will become far poorer as a result of climate change; others are less vulnerable. Some rich states will face serious adverse effects from climate change; others are less vulnerable. Some poor states, and some rich states, may even be net gainers from climate change. Ideally, permits should be distributed in light of these consequences, but the per capita approach fails to take them into account. (2010: 129)

I have two responses to this objection. First, without the precise knowledge about whom will benefit exactly how much more (less) than others from receiving more (fewer) emissions permits than others, it is hard to see why EE fails as a second-level principle for distributions of emissions permits on act-utilitarian grounds. In the

\footnotetext{
${ }^{14}$ Thanks to an anonymous referee for pointing this out.

${ }^{15}$ See Hooker (2013: 243).
} 
absence of such knowledge, it seems rather to be what act-utilitarianism would recommend. A similar response is given by Singer:

The egalitarian principle [i.e. EE] will not, in general, be what utilitarians with perfect knowledge of all the consequences of their actions would chose. Where there is no other clear criterion for allocating shares, however, it can be an ideal compromise that leads to a peaceful solution, rather than continued fighting. (2010: 194)

My second response is that the argument raised by Posner and Weisbach mistakenly presupposes that emissions permits is the most efficient means by which inequalities should be neutralized. However, there is nothing that indicates that existing inequalities between people are best dealt with through differentiated emissions permits. For one thing, using emissions permits as an equalizer in this regard would require a huge knowledge apparatus - not only regarding different people's current possessions of goods, and their different needs, but also regarding their different capacities to convert emissions to welfare. An obviously better candidate in this respect, that is generally used in similar circumstances, is money. ${ }^{16}$

Moreover, EE does not exclude the possibility of trading emissions permits (and other resources). Just because everyone would initially receive an equal share of emissions permits (and other resources) does not mean that they will not trade these resources with one another. Also, EE is not the one and only principle for distributions in general. That is, EE is not supposed to provide recommendations for all sorts of issues, but only for how to distribute emissions permits. For this reason, EE should be considered as one second-level principle among other second-level principles that deal with issues other than those regarding distributions of emissions permits. This moreover opens up for an overarching rectification principle, whose purpose is to rectify other misfortunes for the sake of welfare maximization. Hence, there is support to be given for EE on utilitarian grounds.

\subsection{Fairness Arguments}

EE can find support also from theories of fairness. There are at least three fairness arguments to be given for EE: (i) a universalizability argument, (ii) a "veil of ignorance" argument, and (iii) an argument from procedural justice. Although none of these arguments alone yields conclusive support to EE, they at least provide some inductive support.

The first fairness argument for EE - the universalizability argument - relates to Kantian theory of morality. On this theory, we should understand EE as a maxim for distribution of emissions permits. We may then run the Kantian universalizability test in order to determine EE's plausibility on Kantianism. Since everyone could reasonably will to emit an equal per capita share of the total amount of greenhouse gases that the atmosphere can absorb, EE's recommendation is universalizable. Of course, there might be other principles for distribution of emissions permits that passes this test too, for which reason we cannot conclude that EE is the principle that Kantianism recommends. Still, this test indicates that EE is at least compatible with a Kantian conception of fairness.

The second fairness argument, going back to Rawls (1971), is that a distribution along the lines of EE is what rational and self-interested agents would choose behind "a veil of

\footnotetext{
${ }^{16}$ Interestingly, Caney discusses money as a distributive resource (e.g. 2012: 281). But he does not say why we should not distribute emission permits equally, and then redistribute money to deal with remaining inequalities.
} 
ignorance". Under the veil of ignorance, no one knows his position in a global society. And under the veil, proposals for competing principles are debated. Now, given that any emissions distribution different from that of EE would imply that some people received fewer emissions rights than they would receive from EE, and given that people behind the veil of ignorance would choose distributions in line with the maximin principle, EE would be chosen. The reason is that $\mathrm{EE}$ would ensure that the worst off were less worse off with respect to emissions permits than they would have been with any other emissions distribution.

One could perhaps object to this argument that what matters according to the maximin principle, and what matters to people behind the veil of ignorance, is not emissions permits in particular. Rather, what matters is that the worst off are made better off in general. Hence, it is not clear that EE would be chosen behind the veil of ignorance. The crucial question is whether EE could be part of a distribution scheme that would make the worst off as well off as possible. As was mentioned above in section 3.2, however, the principle of diminishing marginal utility, and the fact that $\mathrm{EE}$ is compatible with other principles that deal with distributions of other resources, suggests that $\mathrm{EE}$ is well in line with such a distribution scheme. At the very least, it is hard to dismiss EE on the basis of a "veil of ignorance" argument.

The third fairness argument for EE can be inferred from the literature on procedural justice, also going back to Rawls (1971). The argument goes roughly as follows: If we do not know, or cannot agree on, what is the normative ground for just shares, we may be able to agree on a procedure that is fair. The outcome provided by that procedure can then be morally motivated by reference to the fairness of that procedure. One considerably fair procedure for dividing cakes, for instance, is to randomly pick someone who cuts the cake and then let that person be the last to choose a piece of the cake. Assuming that the person both wants as large share as possible, and is somewhat skilled in cutting cakes, an equal distribution will be the result. Given that the same holds not only for cakes, but for goods in general, this procedural justice argument supports an equal division of emissions permits too.

One might object that a division along the lines of $\mathrm{EE}$ is implausible in cases where some have already eaten up part of the cake prior to the actual division. This objection applies to the climate case, since some people have historically used more of the atmospheric absorptive capacity than others. In response to this objection, however, it may be argued that $\mathrm{EE}$ is a history-sensitive approach, which takes historical emissions into account. I will get back to this below, in section 4.2 , as it relates to an argument regarding political feasibility.

Summing up this section, it seems clear enough that principled arguments can be given for EE. Let us now move to the pragmatic arguments concerning EE.

\section{Pragmatic Arguments for EE}

As we saw in section 2, the plausibility of EE depends not only on principled arguments, or, in other words, the extent to which EE can be said to fulfill the "desirability condition". It also depends in part on pragmatic arguments, or, in other words, the extent to which EE can be said to fulfill the "achievability condition". Many objectors to EE have argued that it fails to meet this condition too. More specifically, it has been argued that (i) EE is impracticable, (ii) EE is politically unfeasible, and (iii) EE fails to reach its goal. In this section, I defend EE from these charges. 


\subsection{EE is notImpracticable}

One argument against the practicality of EE, discussed by Posner and Weisbach (2010: 137138) as well as by Margalioth and Rudich (2013: 196), points out that the atmospheric capacity is in part determined by other natural carbon sinks on earth, such as forests, oceans and lakes. Since forests and lakes, at least, are typically owned legally by sovereign states, it is implausible to consider them as something that should at all be divided equally among people. Since such a division between the atmospheric capacity and the other natural carbon sinks appears to be suggested by the equal per capita view, they think this view is impracticable.

There are at least four ways to answer this objection. First, it can be questioned whether the forests and the lakes that are situated within national territories belong morally to these respective nations. As Posner and Weisbach themselves suggest, "[p]eople should not gain or lose because of the contingency of the location of their birth, and so there is no ethical reason for giving states control over resources that happen to be located on their territory" (2010: 137). If this can be argued, then it makes sense to claim that this capacity should still be divided equally among people. Second, even if the forests and lakes that are situated within national territories would belong morally to these nations, for which reason they should not be divided equally among people globally, it could be argued that these resources' capacity to absorb greenhouse gas is still something that belongs morally to everyone. Third, it is in any case meaningful to discuss the atmosphere's absorptive capacity in isolation from other natural carbon sinks. Even without forests and lakes, the atmosphere functions as a container into which greenhouse gases can be emitted for decomposition. Fourth, the objection at issue does not target only EE, but any principle for distribution of emissions permits (including the grandfathering principle and the subsistence principle). Hence it does not settle the battle between these principles.

Roser and Seidel provide another, however similar, argument against EE's practicality. They say that "it becomes apparent on closer inspection that equal shares are not so easy to calculate after all, because the population and the emissions budget changes over time" (2017: 157). Their claim is that the exact number of people that are simultaneously living on the planet will vary from one year to another, and that a similar variation holds also regarding the atmospheres absorptive capacity. The variation of the latter capacity is due to such things as speed of deforestation, the capacity of the oceans to absorb greenhouse gasses, and natural emissions from melting perm frosts, etcetera.

Just as with the previous objection, however, this does not affect EE in particular. It affects any distribution principle for emissions permits: Any share, whether equal or not, will be hard to calculate. What is more, it seems that the alternatives to EE fares even worse from the perspective of practicality, since these principles will have to determine also people's different reliance (as the grandfathering principle requires) or needs (as the subsistence principle requires) or whatever they would take into direct consideration (such as capabilities, costs, benefits, or etc.) besides the size of the population and the size of the emissions budget. ${ }^{17}$

For the better, however, it seems that none of these practicality objections are sound. Indeed, EE could be assumed to work from some fixed numbers regarding population sizes and carbon budget sizes - plausibly corresponding to estimates made by the UN. This is suggested by Singer (2010: 195) and Broome (2012: 70-72). It should be fairly easy to make at least approximations for each year, regarding how much the equal per capita share of

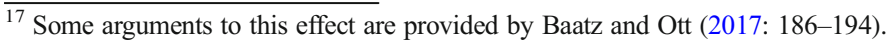


emissions amounts to. Since we are contended with such approximations when it comes to divisions of other resources (e.g., fish stocks), they should be sufficient also when it comes to divisions of emissions permits.

\subsection{EE is not Politically Unfeasible}

Caney raises a feasibility objection against EE, claiming that "[d]eveloping countries, in particular the so-called BASIC bloc (which comprises Brazil, South Africa, India, and China), are deeply opposed to an Isolationist approach. They argue that an equitable distribution of greenhouse gas emissions must take into account different countries' needs" (2012: 278-9). The idea is that, since EE treat emissions permits in isolation from different countries' different needs, developing nations will never agree to a climate treaty along the lines of EE.

We should recall from section 3.2, however, that EE is compatible with other principles aimed at addressing existing inequalities. And, more importantly, the equal per capita view can be considered an history-sensitive approach, according to which current and future allocations of emission permits should take past emissions into account. Given the unequal past emissions of different countries, the overall equal distribution suggested by a history-sensitive version of EE implies that future emissions permits should not be distributed equally - at least until an equilibrium is reached. This has the effect that, to quote Broome, "[t]hose who have already taken up a lot of space by emitting greenhouse gas in the past will consequently receive fewer annual permits to emit in the future" (2012: 70).

Since the present differences in needs between people are closely connected to their respective countries' development stage, which in turn is closely related to their historical emissions, the history-sensitive version of EE will account for this difference. For, once differences in historical emissions have been considered, the amount of emissions that poor countries are entitled to will typically exceed the amount that they are actually emitting. Bangladeshis, for instance, who presently emit around 0,5 tons per capita annually will not only be allowed to emit 0,5 tons more but also an additional amount as compensation for their historically low emissions. ${ }^{18}$ Since the number of emissions permits that they do not need to use themselves can be sold to other countries, the revenues could be used to satisfy the needs of the Bangladeshis.

Still, Posner and Weisbach argue against EE's pragmatic prospects from the other way around: That EE will be rejected by rich nations. They say: "Per capita allocations would have the effect of redistributing hundreds of billions of dollars from wealthy nations, above all the United States, to developing nations. For this reason, insistence on per capita allocations would effectively doom any climate change agreement" (2010: 122). ${ }^{19}$

My response to this objection is, simply, that EE does not require that high emitting nations transfer money to low emitting nations. EE only requires that each nation emits only as much as is consistent with an equal per capita share of emissions permits. Sure, one way to do so is to purchase emissions permits from poor countries. But another way is to transfer new technology to them as a means of emissions offsetting. For, by doing so, a rich country can discount its own emissions in proportion to the reductions

\footnotetext{
${ }^{18}$ See Chancel and Piketty (2015). Note that, on the history-sensitive version of EE, the only thing that is compensated is people's unequal historical usages of the atmospheric absorption capacity. Hence, within the framework of EE, the role of compensation is not to correct for damages or impact on human rights, or the like. ${ }^{19}$ A similar argument is raised by Margalioth and Rudich (2013: 194).
} 
it helps other nations to make. Moreover, a rich country could develop its own infrastructure so that it becomes more or less carbon free - e.g. through investing in domestic fossil-free energy production, such as nuclear, biofuel, solar and wind.

Still, Posner and Weisbach (2010: 137-138) raise another feasibility objection against EE. They claim, correctly I think, that EE must be understood as part of a so-called cap and trade solution to the climate crisis. According to the cap and trade idea, climate stability is achieved by a three-step procedure: (i) an emissions cap for all countries together is first determined by international agreement, (ii) this emissions cap is then divided in terms of emissions permits between the individual countries, and (iii) these emissions permits are then either used directly by each nation or sold to other nations. ${ }^{20}$ However, Posner and Weisbach argue that this solution will not be accepted by the international community, partly because there are other solutions that will do a better job in mitigating climate change.

For instance, they argue that a carbon tax is such a solution. According to a carbon tax solution, each emitter pays a tax in proportion to the social costs of their emissions. And this does not require any division of emissions permits in the first place. As they say, "[a] carbon tax forces polluters to bear the costs of emissions, and that is enough" (2010: 55). Moreover, they argue, a cap and trade solution is "...probably less effective than a tax [...]" (2010: 2). If this is correct, then it certainty speaks against the political feasibility of EE.

My reply is threefold. First, the argument in favor of a tax-based solution to the climate crisis relies on empirical speculations about the outcomes of future conventions of the international community. Whether or not these speculations will turn out to be correct, it seems that climate ethicists should not take the risk of investigating only a carbon tax solution. In case the international community would eventually agree on a cap and trade solution rather than a tax solution, it would be a big mistake if climate ethicists had not investigated such a solution. And a cap and trade solution requires an answer to the question of how the atmospheric capacity should be divided, which EE provides.

Second, there is nothing that excludes that a cap and trade system is adopted alongside a tax system. For instance, a tax system could be used within individual nations as a means to make sure that they stay within the emission levels negotiated between nations. Consider the Paris Agreement, which establishes that each country should decide its own ambitions in order to reach a maximum of $2{ }^{\circ} \mathrm{C}$ warming target. Since this target is supposed to imply a maximum of approximately 11 gigatons of greenhouse gas emissions annually, individual nations must still get an answer as to what is their fair share of annual emissions in order to determine their concrete climate ambitions. ${ }^{21}$ And EE provides an answer to this question. Thus, EE can fill an important guiding function for nations. At the very least it provides moral reasons for highemitting nations to accept a climate treaty that requires them to reduce their emissions. ${ }^{22}$

Third, EE is not in itself supposed to solve the climate crisis. Its only purpose is to divide fairly the emissions, provided by the atmospheric absorptive capacity, that are compatible with climate stability. I will get back to this shortly, as it relates to an objection discussed in section 4.3.

A more general defense of EE's political feasibility points out that EE is at the moment a popular principle for distributions of emissions permits. In Caney's words, it is a "widely held"

\footnotetext{
${ }^{20}$ See Broome (2012: 68-69).

${ }^{21}$ See Chancel and Piketty (2015), and IPCC (2014).

22 Sure, Posner and Weisbach might argue that, on pure economic grounds, the cap and trade solution should not be mixed with a carbon tax solution. In the real world of policy making, however, we will see such mixtures. For that reason, the technical debate about instruments will not falsify EE. Thanks to an anonymous referee for pointing this out.
} 
and "perhaps, the dominant view among environmental philosophers and activists" (2012: 259-60). Moreover, EE seems to be the least bad alternative from a pragmatic point of view. A principle that is more biased in favor of rich nations (such as the grandfathering principle) is even more likely to be rejected by poor nations, while a principle that is more biased in favor of poor countries (such as the subsistence principle) is even more likely to be rejected by rich nations. And solving the problem of emissions distributions is presumably easier when considered in isolation than when considered in conjunction with several other problems. The political community will, plausibly, have an easier time agreeing on one thing at a time, than agreeing on all of them at once. When deciding how to distribute emissions permits, it would be an overwhelming task for COP negotiators if they had to take into account all considerations of justice. ${ }^{23}$ For this reason, Singer seems to be right that EE comes out as a winner "because of its simplicity, hence its suitability as a political compromise" (2010: 194).

To be sure, this defense of EE's political feasibility depends on empirical matters. But so too does the feasibility objection in the first place. And, as I have argued here, it is far from obvious that the available empirical evidence speaks against, rather than for, EE.

\subsection{EE does not Fail to Reach its Goal}

There is one final pragmatic worry: Even if EE is neither impractical nor politically unfeasible (in the senses discussed above), EE might still fail to solve the climate crisis. This worry comes in two parts.

The first part is less serious. It stems from the observation that there are at least two different kinds of responsibility regarding the climate crisis: mitigation and adaptation. $^{24}$ Mitigation is about alleviating the causes of climate change, while adaptation is about coping with the effects of unmitigated climate change. Plausibly, solving the climate crisis requires both mitigation and adaptation. Since EE is by most climate ethicists supposed to deal only with climate change mitigation, it could be argued that it cannot suffice to solve the climate crisis. ${ }^{25}$ The simple reply to this part of the worry is that $\mathrm{EE}$ is not alone meant to solve the climate crisis, which is something we shall get back to shortly.

The second part of the worry is trickier. It observes that EE might perhaps not even fulfill the purpose of climate change mitigation. Baatz and Ott, for instance, claim that since the fundamental purpose of climate change mitigation is to make sure that people's rights are not violated, this is also the fundamental purpose of EE (2017: 177-182). They furthermore argue that climate change mitigation will involve measures of climate change adaptation, and that EE will, in virtue of neglecting issues of climate change adaptation, fail to assure that people's rights are not violated by climate change.

My response to this argument is that EE is not fundamentally an instrument for respecting people's rights. If it were, then proponents of theories that do not basically rely on rights - e.g. Singer and Broome - would not be very interested in discussing it. But they are, and the reason

\footnotetext{
${ }^{23}$ The COP (Conference of the Parties) is the supreme decision-making body of the UNFCCC (United Nations Framework Convention on Climate Change). All States that are Parties to this convention are represented at the COP. See: http://unfccc.int/bodies/body/6383.php.

${ }^{24}$ Sometimes compensation is considered a third kind of responsibility with respect to climate change, aimed at correcting for harms that are due to failures to adapt to unmitigated climate change. See Caney (2012). In this paper, however, compensation can be seen as a sub-category of adaptation and thus be left to one side.

${ }^{25}$ See, e.g., Vanderheiden (2008), Risse (2008), Caney (2012), Baatz and Ott (2017).
} 
is that $\mathrm{EE}$ is a principle for distributing emissions permits, period. Of course, if no one emits more than their fair share, then perhaps no one's emissions will violate any one's rights. But that is a side effect, however welcomed. Whether or not it can be shown that EE can make sure that no rights are violated by our emissions, this does not undermine the plausibility of EE.

Moreover, I think that it is a mistake to describe EE as a mitigation principle in the first place. EE is not per se supposed to solve the climate crisis. EE kicks in only after such a goal has been set, with the purpose of dividing fairly the emissions that are provided by the atmospheric absorptive capacity that is compatible with climate stability. As we saw above, EE is only part of a cap and trade solution to the climate crisis. For that reason, it is only in conjunction with the other steps of such a solution that EE can help us reach such a goal. The present objection seems to disregard the context in which EE is supposed to work.

Obviously, the climate does not care who emits. In other words, the climate is not sensitive to how the amounts of sustainable emissions are divided. Climate stability requires only that the total amount of emissions does not exceed the amount that can be naturally absorbed by the atmosphere (i.e. without triggering dangerous climate changes). As this implies, all principles for distributions of emissions permits will fare equally well with respect to climate change mitigation. Although solving the climate crisis is surely part of the motivation for ethicists and political theorists to debate distribution principles for emissions permits, it is a misunderstanding to think that this issue constitutes a tie-breaker in this debate.

\section{Conclusion}

This paper has shown that there are both principled and pragmatic arguments for EE. First, it was argued that EE can find support from left-libertarian, utilitarian, and fairness theories, respectively. Second, it was argued that EE is neither impractical, nor politically unfeasible, and that it does not fail to reach its goal. In summary, there is a case to be made for the view that emissions permits should be divided equally between people. Consequently, and contrary to what some debaters have argued, EE should have a role to play in both climate ethics and climate politics.

Funding Information Open access funding provided by Stockholm University.

Open Access This article is distributed under the terms of the Creative Commons Attribution 4.0 International License (http://creativecommons.org/licenses/by/4.0/), which permits unrestricted use, distribution, and reproduction in any medium, provided you give appropriate credit to the original author(s) and the source, provide a link to the Creative Commons license, and indicate if changes were made.

\section{References}

Attfield R (2003), Environmental ethics: an overview of the twenty-first century, Polity Press (Cambridge)

Baatz C, Ott K (2017) In Defense of Emissions Egalitarianism? In: Meyer L, Sanklecha P (eds) Climate justice and historical emissions. Cambridge University Press, Cambridge, pp 165-197

Bovens L (2011), A lockean defense of grandfathering emission rights. In: Denis A (ed) The ethics of global climate change, Cambridge University Press

Brooks T (2016) How not to save the planet. Ethics, Policy \& Environment 19(2):119-135 
Broome J (2012) Climate Matters - Ethics in a Warming World. W.W. Norton \& Co, New York

Caney S (2005), Justice beyond borders, Oxford University Press

Caney S (2011), Climate change, energy rights, and equality. In: Arnold, Denis G. (ed) The ethics of global climate change, Cambridge University Press

Caney S (2012) Just Emissions. Philos Public Aff 40(4):255-300

Chancel and Piketty (2015) Carbon and inequality: from Kyoto to Paris. Trends in the global inequality of carbon emissions (1998-2013) \& prospects for an equitable adaptation fund. Paris School of Economics, Paris

Hooker B (2013), Rule-Consequentialism, The Blackwell Guide to Ethical Theory, Blackwell Publishing.

IPCC (2014), Climate change 2014: impacts, adaptation, and vulnerability. Part a: global and sectoral aspects. Contribution of Working Group II to the Fifth Assessment Report of the Intergovernmental Panel on Climate Change. Cambridge University Press

Jamieson D (2005) Adaptation, Mitigation, and Justice. In: Sinnot-Armstrong, Howarth (eds) Perspectives on climate change. Emerald Publishing Group, Amsterdam, pp 221-253

Knight C (2013) What is grandfathering? Environmental Politics 22(3):410-427

Margalioth Y, Rudich Y (2013) Close Examination of the Principle of Global Per-Capita Allocation of the Earth's Ability to Absorb Greenhsouse Gas. Theoretical Inquiries in Law 14(1):191-206

Meyer A (1999) The Kyoto Protocol and the Emergence of 'Contraction and Convergence' as a Framework for an International Political Solution to Greenhouse Gas Emissions Abatement. In: Hohmeyer O, Rennings K (eds) Man-made climate change. ZEW Economic Studies Bd. 1, Heidelberg, pp 291-345

Moellendorf D (2011) Common atmospheric ownership and equal emissions entitlements. In: Arnold DG (ed) The ethics of global climate change. Cambridge University Press, Cambridge and New York, pp 104-123

Ott K (2010) Ethical Foundation of climate change policies. In: Bergmann S, Gerten D (eds) Religion and dangerous environmental change. LIT Verlag, Münster, pp 195-203

Ott K and Baatz C (2012), Domains of climate ethics: an overview In: Potthast T and Meisch S (eds.) Climate change and sustainable development: Ethical perspectives on land use and food production, Wageningen Academic Publishers pp. 23-28

Posner E, Weisbach D (2010) Climate change justice. Princeton University Press, Princeton

Rawls J (1971) A theory of justice. Harvard University Press, Cambridge

Risse M (2008), "Who Should Shoulder the Burden? Global Climate Change and Common Ownership of the Earth,” Faculty Research Working Paper Series, Harvard John F. Kennedy School of Government

Roser D and Seidel C (2017), Climate justice: an introduction, Routledge

Shue H (1993) Subsistence emissions and luxury emissions. Law \& Policy 15(1):39-59

Singer P (2010) One atmosphere. In: Gardiner SM, Caney S, Jamieson D, Shue H (eds) Climate ethics - essential readings. Oxford University Press, USA

Steiner H (2009) Left libertarianism and the ownership of natural resources. Public Reason 1(1):1-8

Vallentyne P, and van deer Vossen B (2014), Libertarianism. In: The stanford encyclopedia of philosophy Fall 2014 Edition, Edward N. Zalta (ed.)

Vanderheiden S (2008), Atmospheric justice: a political theory of climate change, Oxford University Press

Publisher's Note Springer Nature remains neutral with regard to jurisdictional claims in published maps and institutional affiliations. 